\title{
EVALUATION OF ACADEMICS' READINESS COMPETENCIES AND NEW ROLES IN SWITCHING TO ONLINE EDUCATION MODEL DURING THE PANDEMIC
}

\author{
Mutlu Soykurt ${ }^{1}$, Fahriye Altınay ${ }^{2}$, Gökmen Dağl ${ }^{3}$ and Zehra Altınay ${ }^{2}$ \\ ${ }^{1}$ Asst. Prof. Dr., University of Kyrenia, Faculty of Education, Kyrenia, Cyprus \\ ${ }^{2}$ Prof. Dr., Near East University, Nicosia, Graduate School of Educational Sciences, Societal Research and Development \\ Center, Cyprus \\ ${ }^{3}$ Prof. Dr., Near East University, University of Kyrenia, Faculty of Education, Cyprus
}

\begin{abstract}
In Covid 19 period, online education becomes visible and becomes necessity for the education. Learners have a right to get educational services. The mode of learning and teaching have changed to online context from traditional context in higher education systems. This research study aims to evaluate the academic readiness competencies and new roles to online education model. Research relies on qualitative research method. Data was collected through semi structured interview to 25 academicians at higher education institution. In addition to this data was analyzed through content analysis in order to reach out the answers of the questions "What are the instructors' views regarding the current effectiveness of the distance education model suggested for use by your institution during the COVID-19 pandemic?, What are the instructors' views regarding the areas that need improvement of the distance education model suggested for

use by your institution during the COVID-19 pandemic? What were the most challenging aspects?, What are your views regarding the betterment of the distance education model suggested for use by your institution during the COVID-19 pandemic? (Instructors' needs, measurement-assessment criteria, etc.). Research revealed that academics encounter problems in transferring their existing pedagogical skills to distance education setting through online instruction model.
\end{abstract}

\section{KEYWORDS}

Academicians, Learning, Online Education, Pandemic Time, Roles, Teaching

\section{INTRODUCTION}

The terms and concepts of online education and blended education have been on the agenda of education at all levels for many years. Despite the large amount of research on this matter, the full extent of the actions needed to be taken or the preparations of educational institutions were not clearly observed until the COVID-19 pandemic outburst. With the quarantines and lockdowns happening in all countries across the world, the concept of emergency education finally helped institutions to put their online education plans into practice (Strielkowski, 2020). The countries and universities which were already in the process of moving to online or blended education when the outbreak started, had to speed up their arrangements and switch to fully online education immediately without much hustle; however, the institutions and countries that had to prior experience in online or even blended education had to plan and take action almost simultaneously without much time and space reserved for detailed and careful planning (Crawford et al., 2020).

Considering that online education can be quite costly for students, especially when their institutions cannot provide adequate infrastructure at low costs or free of charge (Demuyakor, 2020), it is the responsibility of the institutions' and clearly, the instructors' responsibility to provide students with the education they much receive and work hard to pay for. Yet, providing effective online education is not an easy task especially for instructors and institutions that are novice in online education. The roles and competencies expected from the instructors have changed greatly and rapidly with the pandemic and internalization of these competencies and roles play a crucial part in the quality of online teaching and learning (Maor, 2003). The roles and relevant competencies 
of instructors of online teaching can be analyzed in relation to the 'four hats' metaphor each of which represents a different role of instructors: pedagogical hat, social hat, managerial hat and technical hat (Bonk et al, 2001 as cited in Maor, 2003). The pedagogical role refers to presenting feedback and instruction, asking stimulating questions, integrating external materials; the social role represents offering emotional support, establishing rapport with and among students, being positive and ensuring continuous communication; the managerial role consists of organizing different teaching units, assessment and monitoring course structure; lastly, the technical role guides students and colleagues in using technological tools and offers technical assistance to students when needed (Maor, 2003).

The instructors can take on these roles in an effective manner only if they are aware of their own competences and the changes they are needed to make in their teaching beliefs and practices as well as improving their pedagogical knowledge.

In light of the changes taking place in higher education in Northern Cyprus due to the COVID-19 pandemic, the current study aims to evaluate the readiness status of academics in switching to online education during the pandemic within the framework of the opportunities provided by the University of Kyrenia. The study attempts to answer the following research questions;

1. What are the instructors' views regarding the current effectiveness of the distance education model suggested for use by your institution during the COVID-19 pandemic?

2. What are the instructors' views regarding the areas that need improvement of the distance education model suggested for use by your institution during the COVID-19 pandemic? What were the most challenging aspects?

3. What are your views regarding the betterment of the distance education model suggested for use by your institution during the COVID-19 pandemic? (Instructors' needs, measurement-assessment criteria, etc.)

\section{BODY OF PAPER}

\subsection{Study Group}

The working group was used by 25 academicians working at Kyrenia University in Northern Cyprus.

\subsection{Data Collection Process}

The data collection process was conducted in an online manner with 25 academics from the University of Kyrenia in Northern Cyprus. The participants were informed about the aim of the study and that the data collection method would be interviews. The data was collected from the volunteering participants in May 2020. The response time of the participants was approximately 20 minutes.

\subsection{Data Analysis}

The responses gathered from the data collection process were presented in pie charts based on individual categorization. Following this initial categorization, the collected data was analyzed in detail by the researchers to determine the themes and final categories. These themes and categories were then revised based on the review of relevant literature and categories with similar patterns were combined together while categories with different patterns were coded separately. The data collected from the interview questions was analyzed through content analysis. Content analysis is conducted at four stages (Yıldırım and Şimşek, 2011). 


\subsubsection{Coding of the Data}

At the first stage of content analysis, each participant was numbered, their responses were transcribed, divided into meaningful parts within the scope of the study and their conceptual meaning was labeled through codes. The code list which was prepared according to the conceptual framework and interview questions was finalized after reviewing all the data. This code list functioned as a key while organizing the data. The data outside of the questions were not included in the coding. Later on, the key for codes and interview transcripts were reviewed separately by the researchers to discuss 'agreement' and 'disagreement' issues to finalize the arrangements. The reliability calculation for the study was done through Miles and Huberman' (1994) reliability formula and calculated as $90 \%$. Having reliability calculations over $70 \%$ is accepted as reliable for the conducted studies (Miles and Huberman, 1994). This result is accepted as reliable for the study. The codes that had agreement from the researchers were used as the basis for the themes.

\subsubsection{Finding the Themes}

At this stage, the codes determined at the previous stage are accepted as separate categories and interpreted accordingly.

\subsubsection{Organization and Definition of the Data based on the Codes and the Themes:}

The views of participants were explained to the reader in a reader-friendly manner and presented from the first hand. Footnotes were used to determine which participant the views belong to and interview responses are presented within quotation marks.

\subsubsection{Interpretation of the Findings}

The interpretation of the detailed findings by the research and discussion of some results were done at this stage.

\section{CONCLUSION}

First Dimension: Conclusions regarding the transfer of academics' existing pedagogical skills to distance education setting: The conclusions drawn from participants' views and implications for these dimensions are discussed below.

The aim of this study was to evaluate academics' readiness during the on-going distance education process within the opportunities provided by the instructional technology infrastructure used by the universities due to the COVID-19 pandemic in Northern Cyprus. The findings showed that academics encounter problems in transferring their existing pedagogical skills to distance education setting through online instruction model. Similarly, Conrad (2004) also found that teachers depend greatly on their traditional pedagogical knowledge and skills during their online teaching experience as they do not have high awareness of digital pedagogies. In this regard, the academics need in-service training on how to transfer their traditional pedagogical knowledge to online education. It was also noted in the literature that in-service training is a crucial requirement to meet the pedagogical knowledge and skills needs of instructors in online education models (Wilson and Stacey, 2004). Based on the findings, it can be said the academics' readiness in the online education model is not at the desired level. Hence, it is important to plan an in-service training program for academics to help them transfer their existing pedagogical skills into online education. Winarso et al. (2020) highlighted that optimum use of learning platforms heavily rely on teachers' pedagogical knowledge and their ability to transfer traditional instructional methods to online education. It is concluded from the participant responses that there is a significant need to help academics improve their sensitivity and awareness during their course presentations. In support of these recommendations, Rapanta et al. (2020) also discussed that instructors need to be educated on designing materials for online education, work on their social, cognitive and facilitator presence, and have increased knowledge on alternative assessment methods suitable for online education. 
Second Dimension: Conclusions regarding the digital literacy readiness of academics during the distance education process: The conclusions drawn regarding this dimension and relevant implications are discussed below.

The findings indicate that the digital literacy readiness of academics is at a sufficient level but there is room for improvement in accordance with the rapidly changing digital tools and roles. It is also noted that some academics were able to improve their own digital literacy readiness while trying to solve the problems they encountered before asking for support from their institution. As academics face problems despite their existing digital literacy readiness, it is recommended for universities to establish well-organized and specialized distance education centers to support academics when they encounter problems related to their digital literacy during online education to minimize waste of time and effort and ensure effective online education. This suggestion is also supported by Paudel's (2020) study where he reported that digital literacy is a fundamental pre-requisite for educators who provide online education. Another suggestion to hire specialized staff to the existing distance education centers who can provide effective and expert support in increasing academics digital literacy readiness. In parallel to this, another study also found that ICT tools, digital competence of instructors in particular, play an important role in helping teachers adapt to online teaching and improve their technological pedagogical knowledge (Konig, Jager-Biela and Glutsch, 2020).

Third dimension: Conclusions regarding the quality of the teaching-learning process within academics' readiness during distance education: The conclusions drawn from participants' responses and relevant implications for this dimension are presented below.

In light of the findings regarding the quality of the teaching-learning process in terms of academics' readiness during distance education, it can be said that the quality of teaching-learning process decreased during the pandemic. One of the major reasons for the reduced quality of the teaching-learning process is academics' low or no familiarity with the online education model. It is also observed that sufficient training was not received prior to switching to the online education model. Academics conducted online classes in a similar manner to their traditional face-to-face education system and this results in low quality in the online teaching-learning process. In their study with university students, Adnan and Anwar (2020) also reported that online education does not fully achieve its objectives due to instructors' ineffective teaching methods as they are not trained on online teaching methods. These findings suggest that academics' readiness is not at a desired level in the distance education process. Thus, there is an urgent need to improve academics' readiness and the quality of the teaching -learning process in the distance education model. For this purpose, periodical training courses and seminars can be arranged for the academics as part of professional development to improve their online teaching skills. The content of such programs may concentrate on teachers' role as a facilitator and train instructors' on stating clear expectations, having suitable assessment criteria and guiding online peer discussions (Youngblood, Tredde and di Corpo, 2001). In a recent study, Bao (2020) listed five principles for effective online education and these principles can also serve as a framework for in-service training programs for teachers: establishing a connection between the instruction and students' learning style; providing effective delivery; supporting students affectively, cognitively and technically; ensuring interactive participation; and having contingency plans to deal with unexpected problems during online teaching.

Fourth Dimension: Conclusions regarding academics' readiness in terms of teacher-student interaction during distance education process: The conclusions drawn for this dimensions and relevant recommendations are discussed below.

The findings illustrate that $40 \%$ of the participants experienced no productivity in the teacher-student interaction during distance education. Students not being able to see the instructors, in other words, lack of face-to-face meeting with the instructors and low attendance of students in the classes resulted in lower efficacy in the teacher-student relationship than the desired levels. It was suggested by Mao (2003) that instructors are expected to take on the role of a facilitator to improve interaction and establish an online learning community. Fatoni et al. (2020) reported a similar finding from students' perspective reporting that synchronous and interactive rapport between the instructors and students as well as among students needs to be ensured to increase motivation of both parties and effectiveness of online education. One of the major reasons for the low productivity of the teacher-student relationship can be seen as not having academics' readiness at the desired level in the online education model. Thus, universities can bring in experts from the field to help academics increase their readiness in the online education model. Wilson and Stacey (2004) suggested that instructors' awareness regarding the importance of interactive teacher-student communication in online education should be increased and this can be achieved through carefully planned professional development activities. 
Fifth Dimension: Conclusions regarding academics' readiness in terms of productivity during distance education process: The conclusions drawn from participants' responses and related implications are discussed below.

In light of the findings, it can be concluded that $52 \%$ of the academics were productive in terms of their readiness during the distance education process. However, the remaining $48 \%$, almost half of the participants, experienced reduced productivity due to lack of time and increased workload. Similarly, Paudel (2020) reported that although teachers are connected with educators around the globe, they cannot be as productive or innovative in terms of academic research as they desire due to lack of time and reliable equipment in the workplaces. It is understood that academics are not able to concentrate on scientific publications as they spend a lot time in the online education model. Also, increased workload may have led to problems in terms of academics' productivity during distance education process. It can be concluded that as academics' lack of readiness cause low productivity in the online education model. In this regard, it can also be noted that academics do not have effective time-management skills as they had low productivity in the online education model.

In conclusion, universities are suggested to provide training for academics on time-management skills, effective time management and increasing productivity to help them manage their time and academic studies. In relation to both time-management problems and instructors' professional development, Avgerinou and Moros (2020) noted that the pandemic created professional development needs in various areas which are not limited to subject-matter or pedagogical knowledge and may extend to time-management skills and well-being support from colleagues or experts, and that institutions may establish specific units and teams to guide and support teachers towards autonomous professional development and encourage them to join online learning communities to connect with colleagues and increase their productivity through online collaborations.

Despite all the negativities, the students were able to continue their lessons and realize their original designs without losing their motivation to the lesson, with the effect of the extraordinary situation experienced with the COVID-19 epidemic, the distance education method was tried for the first time course with applied content and was successful. Due to the COVID-19 epidemic or events that may disrupt any kind of education that may be experienced, educational institutions should develop curricula and content suitable for the distance education method for practical courses within their body. However, this preparation can only be achieved with the cooperation of teachers, institution officials and experts.

The effectiveness of virtual distribution activities brings to the agenda the effective management of virtual classrooms and what are some of the basic principles and rules in this area, what are and what has been done. Different competencies of pandemic, traditional classroom management principles and practices and virtual classroom management principles and practices show what it requires. Because, instead of encrypted realities, get education in a virtual environment for education. There are research experiments (Alsahrani, Ahmed, \& Ward, 2017) that students' internet use increases the gap in their relationships with lecturers and experts. This result may be due to the social and physical distance of teachers and learners. This will naturally be a reflection of the management in the virtual environment.

Critical thinking about learners and high-level learning to enable teachers to be successful in virtual classroom management. Virtual pedagogy principles for the virtual classroom to help improve learning are needed. These qualities are reflective and collaborative view using tools such as simultaneous-asynchronous classes, interview and conference viewing, through evaluations (Rufai, Alebiosu, \& Adeakin, 2015).

One of the most important challenges in the pandemic period is that teachers for new classes manage the classroom in a virtual environment for learners they have never known yet. This situation, face to face it can be said to be more difficult than the problem. During extracurricular times, messages and reminder announcements can be posted to motivate students. Starting virtual lessons before the learners and greeting all learners who attended the session can have a positive effect. Small virtual communities can be created in which learners can participate. Good training in traditional classroom management and classroom management experiences also play a role in teachers' being effective and successful in virtual classroom management. In addition, technological tools must be sufficient, effective, useful, safe, and can be used effectively by teachers and learners. Educational activities can be organized at all education levels for synchronous and asynchronous learning activities in virtual classrooms. 
After supporting learning, education A second key priority of their institutions is to ensure that their students and well-being and well-being of its staff. Students and educators Maintaining effective social relations between will serve. A prolonged epidemic, individual and multiple effects on the health, income and well-being of communities everyone, including teachers and students There is a possibility that Educators and education systems leaders should make their goals for prosperity clear and visible and significantly improve the lives and health of individuals. in the face of a global health event that will affect should follow strategies to help protect it. Such a this effect is of close concern to every student and teacher. it can affect their motivation and work. This Therefore, to continue learning activities, this is unpredictable where individuals' movements are restricted by maintaining the perception of normality and order in the situation, It can contribute to well-being.

Teachers should be provided with training on virtual classroom management in pre-service and in-service training. The role of teachers, the success of the learning experience physical environment of schools or technological more important than infrastructure. Time provided by schools and When online teaching comes to the fore with the venue the role of teachers, on the contrary, does not decrease. Direct instruction or in the self-learning process, synchronously or through the guidance provided in asynchronous modes, The teacher's role is essential to guide the students.

\section{REFERENCES}

Adnan, M., \& Anwar, K. (2020). Online Learning amid the COVID-19 Pandemic: Students' Perspectives. Online Submission, 2(1), 45-51.

Alsahrani, S., Ahmed, E., \& Ward, R. (2017). The influence of online resources on student- lecturer relationship in higher education: A comparison study. Journal of Computers in Education. 4(2), 87-106. https://link.springer.com/article/10.1007/s40692-017-0083-8 Erişim tarihi: 11.09.2020

Avgerinou, M. D., \& Moros, S. E. (2020). The 5-Phase Process as a Balancing Act During Times of Disruption: Transitioning to Virtual Teaching at an International JK-5 School. Association for the Advancement of Computing in Education, 583-594.

Bao, W. (2020). COVID-19 and online teaching in higher education: A case study of Peking University. Human Behavior and Emerging Technologies, 2(2), 113-115.

Conrad, D. (2004). University instructors' reflections on their first online teaching experiences. Journal of Asynchronous Learning Networks, 8(2), 31-44.

Crawford, J., Butler-Henderson, K., Rudolph, J., Malkawi, B., Glowatz, M., Burton, R., ... \& Lam, S. (2020). COVID-19: 20 countries' higher education intra-period digital pedagogy responses. Journal of Applied Learning \& Teaching, 3(1), $1-20$.

Demuyakor, J. (2020). Coronavirus (COVID-19) and online learning in higher institutions of education: A survey of the perceptions of Ghanaian international students in China. Online Journal of Communication and Media Technologies, 10(3), e202018.

Fatoni, N. A., Nurkhayati, E., Nurdiawati, E., Fidziah, G. P., Adhag, S., Irawan, A. P... \& Azizik, E. (2020). University Students Online Learning System During Covid-19 Pandemic: Advantages, Constraints and Solutions. Systematic Reviews in Pharmacy, 11(7), 570-576.

König, J., Jäger-Biela, D. J., \& Glutsch, N. (2020). Adapting to online teaching during COVID-19 school closure: Teacher education and teacher competence effects among early career teachers in Germany. European Journal of Teacher Education, 43(4), 1-15.

Kuş, E. (2003). Nicel-nitel araştırma teknikleri. Ankara: Anı Yayıncılık.

Legard,R., Keegan,J. \& Word, K. (2003). In-depth interviews. Ritchie \& J. Levis, J. (Edit.). Qualitiative resarch practices. London: Sage publication.

Maor, D. (2003). The teacher's role in developing interaction and reflection in an online learning community. Educational Media International, 40(1-2), 127-138.

Miles, M. B., Huberman, A. M. (1994). Qualitative data analysis: An expanded sourcebook (2nd ed.). California: Sage.

Paudel, P. (2020). Online education: Benefits, challenges and strategies during and after COVID-19 in higher education. International Journal on Studies in Education, 3(2), 70-85.

Rapanta, C., Botturi, L., Goodyear, P., Guàrdia, L., \& Koole, M. (2020). Online university teaching during and after the Covid-19 crisis: Refocusing teacher presence and learning activity. Postdigital Science and Education, 2(3), 923-945. 
Rufai, M.M., Alebiosu, S.O., \& Adeakin, O.A.S. (2015). Conceptual model for virtual classroom management. International Journal of Computer Science, Engineering and Information Technology (IJCSEIT), 5(1), 27-32.

Strielkowski, W. (2020). COVID-19 pandemic and the digital revolution in academia and higher education. doi:10.20944/preprints202004.0290.v1

Wilson, G., \& Stacey, E. (2004). Online interaction impacts on learning: Teaching the teachers to teach online. Australasian journal of educational technology, 20(1), 33-48.

Winarso, W. (2020). Changes in learning patterns during the pandemic covid-19; the case at university $\mathrm{x}$ in Bekasi, west java, Indonesia. International Journal of Advanced Science and Technology, 29(6), 8535-8539.

Yıldırım, A. and Şimşek, H. (2011). Sosyal Bilimlerde Nitel Araştırma Yöntemleri. Ankara: Seçkin Yayıncılık.

Youngblood, P., Trede, F., \& Di Corpo, S. (2001). Facilitating online learning: A descriptive study. Distance Education, 22(2), 264-284. 